\title{
COVID-19 risk index (CRI): a simple and validated emergency department risk score that predicts mortality and the need for mechanical ventilation
}

\author{
Mohamad Raad ${ }^{1}$. Sarah Gorgis ${ }^{1}$. Chelsea Abshire ${ }^{2}$. Monica Yost ${ }^{2} \cdot$ Mohammed F Dabbagh $^{1}$. Omar Chehab ${ }^{3}$. \\ Lindsey Aurora ${ }^{1}$ - Sati Patel ${ }^{1}$ - Paul Nona ${ }^{1}$. Jerry Yan ${ }^{1}$. Gurjit Singh ${ }^{1}$ - John Syrjamaki ${ }^{2}$. Scott Kaatz ${ }^{4}$. \\ Sachin Parikh ${ }^{1}$ (1)
}

Accepted: 31 August 2021 / Published online: 23 September 2021

(c) The Author(s), under exclusive licence to Springer Science+Business Media, LLC, part of Springer Nature 2021

\begin{abstract}
Although certain risk factors have been associated with morbidity and mortality, validated emergency department (ED) derived risk prediction models specific to coronavirus disease 2019 (COVID-19) are lacking. The objective of this study is to describe and externally validate the COVID-19 risk index (CRI). A large retrospective longitudinal cohort study was performed to analyze consecutively hospitalized patients with COVID-19. Multivariate regression using clinical data elements from the ED was used to create the CRI. The results were validated with an external cohort of 1799 patients from the MICOVID19 database. The primary outcome was the composite of the need for mechanical ventilation or inpatient mortality, and the secondary outcome was inpatient mortality. A total of 1020 patients were included in the derivation cohort. A total of 236 (23\%) patients in the derivation cohort required mechanical ventilation or died. Variables independently associated with the primary outcome were age $\geq 65$ years, chronic obstructive pulmonary disease, chronic kidney disease, cerebrovascular disease, initial D-dimer $>1.1 \mu \mathrm{g} / \mathrm{mL}$, platelet count $<150 \mathrm{~K} / \mu \mathrm{L}$, and severity of $\mathrm{SpO}$ :FiO2 ratio. The derivation cohort had an area under the receiver operator characteristic curve (AUC) of 0.83 , and 0.74 in the external validation cohort Calibration shows close adherence between the observed and expected primary outcomes within the validation cohort. The CRI is a novel disease-specific tool that assesses the risk for mechanical ventilation or death in hospitalized patients with COVID-19. Discrimination of the score may change given continuous updates in contemporary COVID-19 management and outcomes.
\end{abstract}

Keywords COVID-19 $\cdot$ Risk score $\cdot$ Outcomes $\cdot$ Risk factors $\cdot$ SARS-CoV-2

\begin{tabular}{llll}
\multicolumn{2}{l}{ Abbreviations } & ED & Emergency department \\
AUC & Area under the curve & ICU & Intensive care unit \\
CKD & Chronic kidney disease & ROC & Receiver-operating characteristics \\
COPD & Chronic obstructive pulmonary disease & SARS-CoV-2 & Severe acute respiratory syndrome \\
COVID-19 & Coronavirus disease 2019 & & coronavirus-2 \\
CRI & COVID-19 risk index & &
\end{tabular}

Sachin Parikh

Highlights

sparikh2@hfhs.org

1 Division of Cardiovascular Diseases, Henry Ford Hospital, Detroit, MI, USA

2 Department of Public Health and Epidemiology, University of Michigan, Ann Arbor, MI, USA

3 Department of Internal Medicine, Wayne State University, Detroit, MI, USA

4 Division of Hospital Medicine, Henry Ford Hospital, Detroit, MI, USA

- Although certain risk factors have been associated with morbidity and mortality in patients with Coronavirus disease 2019 (COVID-19), emergency department (ED) derived risk prediction models specific to COVID-19 are lacking.

- The CRI is an accurate and validated risk prediction tool scoring system that uses clinical data upon presentation 
to the ED to predict the need for mechanical ventilation or inpatient death.

- Variables independently associated with the primary outcome were age $\geq 65$ years, chronic obstructive pulmonary disease, chronic kidney disease, cerebrovascular disease, initial D-dimer $>1.1 \mu \mathrm{g} / \mathrm{mL}$, platelet count $<150 \mathrm{~K} /$ $\mu \mathrm{L}$, and severity of $\mathrm{SpO} 2: \mathrm{FiO} 2$ ratio.

- The CRI can guide early triage, inform treatment strategies, and empower physician decision-making during the COVID-19 pandemic.

\section{Introduction}

Coronavirus disease 2019 (COVID-19) is caused by the novel severe acute respiratory syndrome coronavirus-2 (SARS-CoV-2), which was first identified in Wuhan, China, in December 2019, and has since caused a global pandemic [1].

The clinical manifestations of COVID-19 vary from asymptomatic to severe disease [2]. In a multicenter case series from New York, $14 \%$ of discharged patients required ICU admission [3], with high inpatient mortality [3]. Data so far has demonstrated that underlying comorbid conditions, inflammatory markers, and hypoxic respiratory failure are associated with a higher incidence of adverse outcomes, including mechanical ventilation and mortality [3-6].

During a pandemic, a mass influx of patients can quickly exhaust available resources overwhelming an entire healthcare system. Under such circumstances, a simple risk model that can accurately predict patient outcomes would be valuable in determining early prognosis and aid in triaging patients presenting to the emergency department (ED). Multiple risk models have been described, but to our knowledge, no large study has been externally validated.

Herein, we describe the characteristics and findings of patients hospitalized for COVID-19 at a tertiary care healthcare system. Our study aimed to develop the COVID-19 risk index (CRI): a pragmatic tool to assess the risk for requiring mechanical ventilation or death upon presentation to the ED. We also aimed to validate the risk model within a larger 38-center external hospital registry.

\section{Materials and methods}

\section{Derivation cohort patient population}

We analyzed the records of patients consecutively admitted to Henry Ford Health System in Southeast Michigan between March and May 2020. Patients selected were $\geq 18$ years of age and were hospitalized with a confirmed SARS-CoV-2 diagnosis. Patients were excluded if they were transferred to or out of our center or developed cardiac arrest prior to presentation. Records were reviewed retrospectively.

SARS-CoV-2 was diagnosed by onsite molecular diagnostic testing for the identification of SARS-CoV-2 RNA using reverse transcription polymerase chain reaction (RTPCR). Our method has been validated against the Centers for Disease Control and Prevention (CDC) reference method to meet or exceed the level of detection required under Food and Drug Administration (FDA) Emergency Use Authorization (EUA) guidelines.

\section{Definition of outcomes}

The primary outcome was a composite of the need for mechanical ventilation or death during hospitalization. The secondary outcome was inpatient mortality.

\section{Definitions of variables and predictor selection}

Variables measured at hospital admission (Table 1) were collected at hospital admission. These variables included demographics, symptoms on admissions, vital signs, comorbidities, laboratory, and radiologic data obtained on admission. Data collection was manually extracted from electronic health records. Symptoms were deemed positive if endorsed within $24 \mathrm{~h}$ of presentation. Laboratory data were manually extracted. Baseline results refer to initial blood samples collected in the ED or the first values within $24 \mathrm{~h}$ of admission. Comorbid conditions were identified based on admission and discharge diagnoses. This study was approved by the Institutional Review Board (IRB \#13774), with a waiver of informed consent. Serum ferritin, D-dimer, creatinine phosphokinase, high-sensitivity troponin-I, and lactate dehydrogenase level cutoffs were used based on the median. Lymphopenia was defined as an absolute lymphocyte count $<1000$ counts/uL [7], and anemia as a hemoglobin level $<11 \mathrm{~g} / \mathrm{dL}$. Troponin levels were categorized according to the upper 99th percentile as per prior work [8]. Immunosuppression was defined as a history of autoimmune disease, immunodeficiency disorders, transplantation, immunosuppressant use (any disease-modifying agent or prednisone $\geq 10 \mathrm{mg}$ or equivalent for more than 14 days), human immunodeficiency virus, or active malignancy. Cardiovascular disease was defined as any coronary artery disease, heart failure, or cardiac arrhythmia. Peripheral capillary oxygen saturation $\left(\mathrm{SpO}_{2}\right)$ values were obtained from pulse oximetry vital logs. For patients not on mechanical ventilation, the fraction of inspired oxygen $\left(\mathrm{FiO}_{2}\right)$ was estimated by multiplying liter flow per minute by 0.03 and adding that to 0.21 , in accordance with original mSOFA investigations [9]. $\mathrm{SpO} 2: \mathrm{FiO} 2$ ratios were categorized similarly to the Berlin criteria for acute respiratory distress syndrome [10]. Data regarding mean arterial pressure, supplemental 
Table 1 Clinical characteristics of patients on presentation from the derivation cohort

\begin{tabular}{|c|c|c|c|c|}
\hline \multirow[t]{3}{*}{ Variable } & \multicolumn{3}{|c|}{ Primary Outcome } & \multirow[t]{3}{*}{$P$ value } \\
\hline & \multicolumn{3}{|c|}{ Mechanical Ventilation or Death } & \\
\hline & $\begin{array}{l}\text { Overall } \\
\mathrm{N}(\%)\end{array}$ & $\begin{array}{l}\text { With } \\
\text { N (\%) }\end{array}$ & $\begin{array}{l}\text { Without } \\
\mathrm{N}(\%)\end{array}$ & \\
\hline Total No. of observations (\%) & 1020 & 236 & 784 & \\
\hline \multicolumn{5}{|l|}{ I. Demographic characteristic } \\
\hline Age (years), Median & $63(51-73)$ & $72(62-81)$ & $60(50-70)$ & $<0.001$ \\
\hline$\geq 65$ & $471(46 \%)$ & $160(68 \%)$ & $311(40 \%)$ & $<0.001$ \\
\hline \multicolumn{5}{|l|}{ Gender } \\
\hline Female-No. $(\%)$ & $511(50 \%)$ & $101(42 \%)$ & $410(52 \%)$ & 0.011 \\
\hline Male-No. $(\%)$ & $509(50 \%)$ & $135(57 \%)$ & $374(48 \%)$ & \\
\hline \multicolumn{5}{|l|}{ Race-No. $(\%)$} \\
\hline White & $403(40 \%)$ & $80(34 \%)$ & $323(41 \%)$ & 0.132 \\
\hline Black & $463(45 \%)$ & $117(50 \%)$ & $346(44 \%)$ & \\
\hline Body mass index & $31(26-37)$ & $30(26-36)$ & $32(27-37)$ & 0.069 \\
\hline \multicolumn{5}{|l|}{ II. Vital signs and oxygenation on admission } \\
\hline Mean arterial pressure $(\mathrm{mmHg})$ & $88(78-98)$ & $83(74-93)$ & $88(78-98)$ & $<0.001$ \\
\hline $\mathrm{SPO}_{2}: \mathrm{FiO}_{2}$ Ratio & $\begin{array}{l}339 \\
(267-452)\end{array}$ & $\begin{array}{l}247 \\
(140-330)\end{array}$ & $\begin{array}{l}394 \\
(303-457)\end{array}$ & $<0.001$ \\
\hline$>400$ & $419(42 \%)$ & $38(16 \%)$ & $381(49 \%)$ & Reference \\
\hline$>300$ to $\leq 400$ & $245(24 \%)$ & $40(17 \%)$ & $205(26 \%)$ & 0.006 \\
\hline$>200$ to $\leq 300$ & $231(23 \%)$ & $71(31 \%)$ & $159(20 \%)$ & $<0.001$ \\
\hline$>100$ to $\leq 200$ & $85(8 \%)$ & $50(21 \%)$ & $35(5 \%)$ & $<0.001$ \\
\hline$\leq 100$ & $40(4 \%)$ & $36(15 \%)$ & $4(1 \%)$ & $<0.001$ \\
\hline \multicolumn{5}{|l|}{ III. Symptoms on admission } \\
\hline Chest pain & $156(15 \%)$ & $24(10 \%)$ & $132(17 \%)$ & 0.013 \\
\hline Fever & $539(53 \%)$ & $102(43 \%)$ & $437(56 \%)$ & $<0.001$ \\
\hline Cough & $679(67 \%)$ & $141(60 \%)$ & $538(69 \%)$ & 0.011 \\
\hline Shortness of breath & $686(67 \%)$ & $167(71 \%)$ & $519(66 \%)$ & 0.190 \\
\hline GI symptoms & $366(36 \%)$ & $58(25 \%)$ & $308(39 \%)$ & $<0.001$ \\
\hline \multicolumn{5}{|l|}{ IV. Comorbid conditions } \\
\hline Hypertension & $742(73 \%)$ & $193(82 \%)$ & $549(70 \%)$ & $<0.001$ \\
\hline Diabetes mellitus & $453(44 \%)$ & $122(52 \%)$ & $331(42 \%)$ & 0.010 \\
\hline Cerebrovascular disease & $80(8 \%)$ & $40(17 \%)$ & $40(5 \%)$ & $<0.001$ \\
\hline Coronary artery disease & $123(12 \%)$ & $45(19 \%)$ & $79(10 \%)$ & $<0.001$ \\
\hline Heart failure & $127(13 \%)$ & $46(20 \%)$ & $81(10 \%)$ & $<0.001$ \\
\hline Atrial fibrillation/flutter & $66(6 \%)$ & $33(14 \%)$ & $33(4 \%)$ & $<0.001$ \\
\hline Chronic kidney disease & $309(30 \%)$ & $117(50 \%)$ & $192(25 \%)$ & $<0.001$ \\
\hline Smoking history & $361(35 \%)$ & $107(45 \%)$ & $254(32 \%)$ & $<0.001$ \\
\hline Chronic obstructive pulmonary disease & $105(10 \%)$ & $42(18 \%)$ & $63(8 \%)$ & $<0.001$ \\
\hline Obstructive sleep apnea & $90(9 \%)$ & $21(9 \%)$ & $69(9 \%)$ & 0.963 \\
\hline Asthma & $104(10 \%)$ & $17(7 \%)$ & $87(11 \%)$ & 0.083 \\
\hline Chronic hypoxic respiratory failure & $30(3 \%)$ & $15(6 \%)$ & $15(2 \%)$ & $<0.001$ \\
\hline Immunosuppression & $155(15 \%)$ & $52(22 \%)$ & $103(13 \%)$ & 0.001 \\
\hline Cirrhosis & $8(1 \%)$ & $4(2 \%)$ & $4(1 \%)$ & 0.071 \\
\hline \multicolumn{5}{|l|}{ V. Medications } \\
\hline Anticoagulant & $96(9 \%)$ & $35(15 \%)$ & $61(8 \%)$ & 0.001 \\
\hline ACEi/ARB & $361(35 \%)$ & $86(36 \%)$ & $275(35 \%)$ & 0.701 \\
\hline Insulin & $158(16 \%)$ & $51(23 \%)$ & $107(14 \%)$ & 0.001 \\
\hline Statin & $428(42 \%)$ & $107(45 \%)$ & $321(41 \%)$ & 0.230 \\
\hline
\end{tabular}


Table 1 (continued)

\begin{tabular}{|c|c|c|c|c|}
\hline \multirow[t]{3}{*}{ Variable } & \multicolumn{3}{|l|}{ Primary Outcome } & \multirow[t]{3}{*}{$P$ value } \\
\hline & \multicolumn{3}{|c|}{ Mechanical Ventilation or Death } & \\
\hline & $\begin{array}{l}\text { Overall } \\
\mathrm{N}(\%)\end{array}$ & $\begin{array}{l}\text { With } \\
\text { N (\%) }\end{array}$ & $\begin{array}{l}\text { Without } \\
\mathrm{N}(\%)\end{array}$ & \\
\hline \multicolumn{5}{|l|}{ V. Laboratory data } \\
\hline Sodium (mmol/L) & $136(133-138)$ & $\begin{array}{l}136 \\
(133-138)\end{array}$ & $135(133-138)$ & $<0.001$ \\
\hline Potassium (mmol/L) & $3.9(3.6-4.4)$ & $4.1(3.7-4.6)$ & $3.9(3.5-4.3)$ & $<0.001$ \\
\hline Creatinine (mg/dL) & $1.12(0.84-1.78)$ & $1.48(1.04-2.46)$ & $1.07(0.83-1.61)$ & 0.003 \\
\hline White blood cell count $(\mathrm{K} / \mu \mathrm{L})$ & $6.4(4.7-8.9)$ & $7(5.3-10.0)$ & $6.2(4.6-8.6)$ & 0.032 \\
\hline Lymphocytes $(\mathrm{K} / \mu \mathrm{L})$ & $0.9(0.6-1.2)$ & $0.8(0.5-1.1)$ & $0.9(0.6-1.2)$ & 0.610 \\
\hline Hemoglobin $(\mathrm{g} / \mathrm{dL})$ & $13.0(11.7-14.3)$ & $12.7(11.3-14.2)$ & $13.1(11.9-14.4)$ & 0.003 \\
\hline Anemia & $283(28 \%)$ & $84(36 \%)$ & $199(25 \%)$ & 0.002 \\
\hline Platelet count $(\mathrm{K} / \mu \mathrm{L})$ & $202(155-271)$ & $181(140-252)$ & $205(157-271)$ & 0.001 \\
\hline Thrombocytopenia & $232(23 \%)$ & $73(31 \%)$ & $159(20 \%)$ & 0.001 \\
\hline Alanine aminotransferase (IU/L) & $23.5(15-38)$ & $25(16-37)$ & $23(15-38)$ & 0.123 \\
\hline Aspartate aminotransferase (IU/L) & $36(25-57)$ & $45(30-74)$ & $35(24-54)$ & $<0.001$ \\
\hline Total bilirubin $(\mathrm{mg} / \mathrm{dL})$ & $0.6(0.4-0.8)$ & $0.6(0.4-0.9)$ & $0.6(0.4-0.8)$ & 0.734 \\
\hline Albumin (mg/dL) & $3.5(3.2-3.8)$ & $3.3(2.9-3.6)$ & $3.6(3.3-3.8)$ & $<0.001$ \\
\hline Lactate dehydrogenase (IU/L) & $348(259-472)$ & $418(294-569)$ & $336(256-447)$ & 0.063 \\
\hline Ferritin (ng/mL) & $519(257-1050)$ & $680(313-1426)$ & $483(241-950)$ & 0.001 \\
\hline D-dimer $(\mu \mathrm{g} / \mathrm{mL})$ & $1.30(0.73-2.46)$ & $2.11(1.20-3.75)$ & $1.12(0.63-2.13)$ & $<0.001$ \\
\hline High sensitivity troponin-I (ng/L) & $17(6-32)$ & $28(14-75)$ & $13(5-24)$ & 0.003 \\
\hline Cardiac injury & $390(38 \%)$ & $150(63 \%)$ & $240(31 \%)$ & $<0.001$ \\
\hline \multicolumn{5}{|l|}{ VI. Chest imaging findings } \\
\hline Normal & $144(14 \%)$ & $25(11 \%)$ & $119(15 \%)$ & Reference \\
\hline Unilateral pneumonia & $135(13 \%)$ & $30(13 \%)$ & $105(13 \%)$ & 0.309 \\
\hline Bilateral pneumonia & $224(22 \%)$ & $53(23 \%)$ & $171(22 \%)$ & 0.150 \\
\hline Multi-focal pneumonia & $517(51 \%)$ & $128(54 \%)$ & $389(50 \%)$ & 0.064 \\
\hline
\end{tabular}

$A C E i$ angiotensin converting enzyme inhibitors, $A R B$ angiotensin receptor blockers

oxygen delivery, and Glasgow Coma Scale were ascertained from ED vital logs.

A univariate analysis was performed, and the variables that were significantly associated with our primary outcome were included in logistic regression. The variables that remained statistically associated $(P \leq 0.05)$ with the primary outcome after multivariable regression were used to create the CRI index.

\section{Statistical analysis}

Statistical Package for Social Sciences (SPSS, version 25, IBM, Armonk, New York) and Statistical Analysis Software (SAS) was used for data cleaning and analysis. The data were analyzed by independent statisticians: O.C. and E.P. for the derivation cohort and C.A. and M.Y. for the validation cohort. Descriptive statistical analyses were obtained for all included study variables and are summarized in Supplementary Table 1. Categorical variables are expressed as frequency or percentage, whereas continuous variables are presented as mean and standard deviation or median and interquartile range based on the normality of the data. First, univariate analysis was performed by using $\chi^{2}$ test or Fisher exact test for categorical variables and the T-test or the Mann-Whitney U test for continuous variables. Multivariate logistic regression analysis using the backward Wald's method was then performed to identify the significant variables to be included in the CRI to predict the primary outcome. Different groups among the CRI scores were compared using $\chi 2$ test for categorical variables and analysis of variance or Kruskal Wallis tests for continuous variables based on the normality of the data. Then, the time-toevent analysis was performed using Kaplan-Meier curves, where significance was calculated using the log-rank test. A 
receiver-operating characteristics (ROC) curve was added to address the discriminatory power of the CRI, and the area under the ROC curve was reported. Statistical analyses were considered significant if $P<0.05$.

\section{Validation cohort}

The newly developed index was validated with the MICOVID19 database. The MI-COVID-19 database is a statewide multiple health system collaborative quality initiative (CQI) that was sponsored by Blue Cross Blue Shield of Michigan and Blue Care Network. The aim of this initiative was to improve the quality of hospitalized patients with COVID-19. The database includes 38 hospitals across the state of Michigan. The median bed size is 391 (IQR:
250-537), 81\% are non-profit, and 93\% self-identify as teaching hospitals. Patients admitted at the Henry Ford Hospital system (used as a derivation cohort) were excluded. The same inclusion and exclusion criteria as the derivation cohort were applied. Validation and the creation of ROC curves were performed through logistic regression modeling. Calibration was performed in a similar fashion. Each patient was assessed for the number of significant factors (as defined in the original cohort) that were affecting them at the time of admission and assigned a score. The total score compared to the outcome was first assessed for each patient as an unadjusted rate. Logistic regression was then used to estimate the predicted probabilities of having the outcome compared to the total score. These predicted probabilities were used to calculated adjusted rates of the outcome within each score
Fig. 1 A The discriminatory power for the COVID-19 risk index (CRI) within the derivation (A) and validation (B) cohorts by receiver-operating characteristic (ROC) area under the curve (AUC)
A

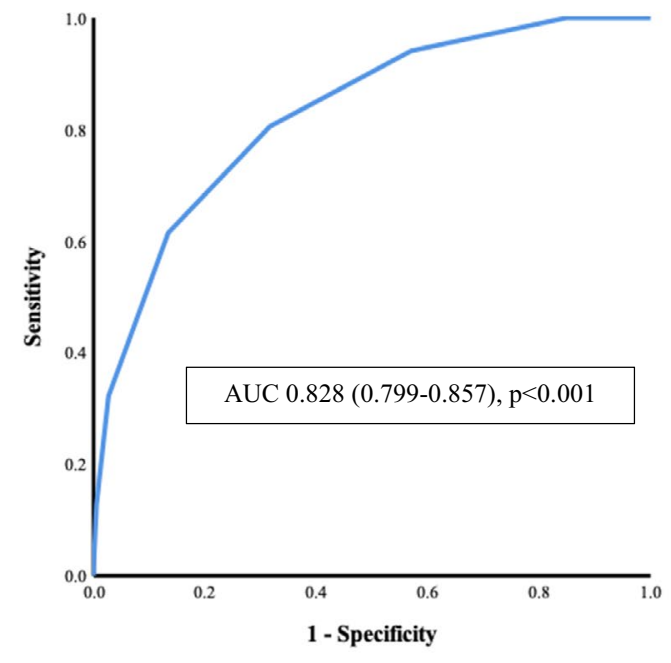

B.

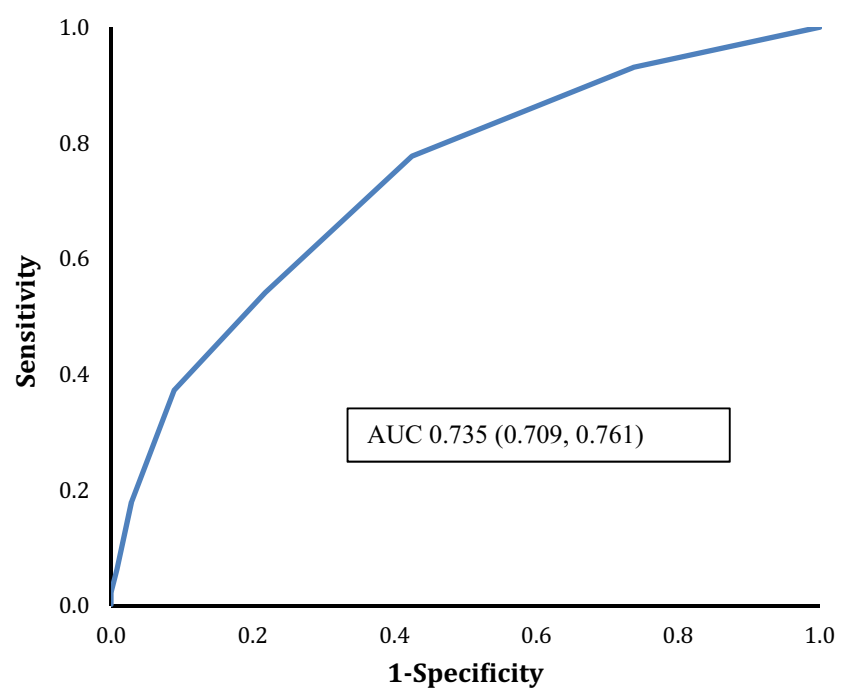


category. Finally, the unadjusted rates were compared to the adjusted rates (Fig. 1).

\section{Results}

We reviewed the charts of a total of 1024 patients admitted between March 8 and May 1, 2020. Of those, three were transferred in or out of our institution, and one presented with cardiac arrest and were therefore excluded. A total of 1020 patients were included in the final analysis for the derivation cohort. Table 1 shows the baseline clinical characteristics of the overall derivation cohort and is categorized into those with or without the primary outcome of death or need for mechanical ventilation. Characteristics included demographics, symptoms on presentation, comorbid conditions, medications, and laboratory/imaging data.
Using the significant univariate predictors, a multivariate logistic regression analysis was performed to identify the independent predictors of our primary outcome. Variables included in the multivariate regression model included: age $\geq 65$, gender, body mass index, hypertension, smoking history, diabetes mellitus, cardiovascular disease, chronic obstructive pulmonary disease, history of immunosuppression, anemia, chronic kidney disease, ferritin $\geq 600(\mathrm{ng} / \mathrm{mL})$, troponin $>18(\mathrm{ng} / \mathrm{dL})$, D-dimer $\geq 1.1$ $(\mu \mathrm{g} / \mathrm{mL})$, creatinine phosphokinase $\geq 10$ (IU/L), lactate dehydrogenase $\geq 340$ (IU/L), and $\mathrm{SpO}_{2}: \mathrm{FiO}_{2}$ categories (Table 1). Of these variables, the significant multivariate predictors were age $\geq 65$ years, chronic obstructive pulmonary disease, chronic kidney disease, cerebrovascular disease, initial D-dimer $>1.1 \mu \mathrm{g} / \mathrm{mL}$, platelet count $<150 \mathrm{~K} / \mu \mathrm{L}$, and severity of $\mathrm{SpO} 2$ :FiO2 ratio (Derivation cohort: Table 2, Validation cohort: Table 4). These variables were used to derive the CRI.

Table 2 Multivariable predictors of death or intubation in the COVID-19 risk index (CRI) derivation cohort

\begin{tabular}{lll}
\hline CRI predictors & $\begin{array}{l}\text { Univariate regression } \\
\text { OR }(95 \% \mathrm{CI}), P \text { value }\end{array}$ & $\begin{array}{l}\text { Multivariate regression } \\
\text { AdjOR }(95 \% \mathrm{CI}), P \text { value }\end{array}$ \\
\hline Age $(\geq 65$ years $)$ & $3.20(2.35-4.36),<0.001$ & $1.76(1.17-2.63), 0.006 \quad+1.78(1.15-2.76), 0.010 \quad+1$ \\
Thrombocytopenia $<150 \mathrm{~K}$ & $3.20(2.35-4.36),<0.001$ & $1.97(1.28-3.03), 0.002$ \\
D-dimer initial $\geq 1.1(\mu \mathrm{g} / \mathrm{mL})$ & $3.61(2.53-5.15),<0.001$ & $2.24(1.49-3.36),<0.001$ \\
Chronic kidney disease & $3.03(2.24-4.10),<0.001$ & $1.77(1.04-3.00), 0.034$ \\
Chronic obstructive pulmonary disease & $2.48(1.63-3.78),<0.001$ & $3.06(1.71-5.47),<0.001$ \\
Cerebrovascular disease & $3.83(2.40-6.10),<0.001$ & $2.16(1.25-3.73), 0.006$ \\
SpO2/FiO2 ratio $>300$ to $\leq 400$ & $1.96(1.22-3.15), 0.006$ & $4.82(2.92-7.97),<0.001$ \\
SpO2/FiO2 ratio $>200$ to $\leq 300$ & $4.54(2.94-7.01),<0.001$ & $12.44(6.62-23.38),<0.001$ \\
SpO2/FiO2 ratio $\leq 200$ & $22.11(13.35-36.61),<0.001$ & +1 \\
\hline
\end{tabular}

Multivariable predictors of the primary outcome, mechanical ventilation or death, in the COVID-19 risk index (CRI) derivation cohort. Variable controlled for: Age $\geq 65$ years, Hypertension, Diabetes Mellitus, Immunosuppressed state, Chronic Obstructive Pulmonary Disease, Chronic Kidney Disease, Coronary Artery Disease, Atrial fibrillation/ flutter, Cerebrovascular Disease, Chronic Hypoxic Respiratory Failure, Smoking History, SPO2:FiO2 Category, Hypotension (MAP $<65 \mathrm{mmHg}$ ), LDH $\geq 700$, D-dimer $\geq 1.1$, Cardiac Injury, thrombocytopenia $<150 \mathrm{~K}$, Anemia $(\mathrm{Hb}<12)$, Ferritin $\geq 700$. The CRI score is computed by adding the points allocated to CRI predictor with a minimum of 0 and maximum of 10 total points

Table 3 Primary outcome within different score groups within CRI categories

\begin{tabular}{|c|c|c|c|c|c|c|c|c|}
\hline \multirow[t]{2}{*}{ Variable } & \multicolumn{8}{|l|}{ Score } \\
\hline & 0 & 1 & 2 & 3 & 4 & 5 & 6 & $\geq 7$ \\
\hline $\begin{array}{l}\text { COVID risk index-No/total }(\%)-\text { derivation cohort } \\
\text { (mechanical ventilation or mortality) }\end{array}$ & $\begin{array}{l}0 / 118 \\
(0 \%)\end{array}$ & $\begin{array}{l}14 / 233 \\
(6 \%)\end{array}$ & $\begin{array}{l}32 / 231 \\
(14 \%)\end{array}$ & $\begin{array}{l}45 / 188 \\
(24 \%)\end{array}$ & $\begin{array}{l}69 / 153 \\
(45 \%)\end{array}$ & $\begin{array}{l}46 / 63 \\
(73 \%)\end{array}$ & $\begin{array}{l}26 / 30 \\
(87 \%)\end{array}$ & $\begin{array}{l}4 / 4 \\
(100 \%)\end{array}$ \\
\hline $\begin{array}{l}\text { COVID risk index-No/total (\%)—derivation cohort } \\
\text { (inpatient mortality only) }\end{array}$ & $\begin{array}{l}0 / 118 \\
(0 \%)\end{array}$ & $\begin{array}{l}9 / 233 \\
(4 \%)\end{array}$ & $\begin{array}{l}23 / 231 \\
(11 \%)\end{array}$ & $\begin{array}{l}32 / 188 \\
(17 \%)\end{array}$ & $\begin{array}{l}51 / 153 \\
(33 \%)\end{array}$ & $\begin{array}{l}37 / 63 \\
(59 \%)\end{array}$ & $\begin{array}{l}21 / 30 \\
(70 \%)\end{array}$ & $\begin{array}{l}4 / 4 \\
(100 \%)\end{array}$ \\
\hline $\begin{array}{l}\text { COVID risk index-No/total (\%)—validation cohort } \\
\text { (mechanical ventilation or mortality) }\end{array}$ & $\begin{array}{l}33 / 381 \\
(9 \%)\end{array}$ & $\begin{array}{l}73 / 487 \\
(15 \%)\end{array}$ & $\begin{array}{l}112 / 386 \\
(29 \%)\end{array}$ & $\begin{array}{l}80 / 250 \\
(32 \%)\end{array}$ & $\begin{array}{l}92 / 172 \\
(53 \%)\end{array}$ & $\begin{array}{l}55 / 82 \\
(67 \%)\end{array}$ & $\begin{array}{l}19 / 30 \\
(63 \%)\end{array}$ & $\begin{array}{l}11 / 11 \\
(100 \%)\end{array}$ \\
\hline $\begin{array}{l}\text { COVID risk index-No/total (\%)—validation cohort } \\
\text { (inpatient mortality only) }\end{array}$ & $\begin{array}{l}11 / 381 \\
(3 \%)\end{array}$ & $\begin{array}{l}54 / 487 \\
(11 \%)\end{array}$ & $\begin{array}{l}95 / 386 \\
(25 \%)\end{array}$ & $\begin{array}{l}64 / 250 \\
(26 \%)\end{array}$ & $\begin{array}{l}74 / 172 \\
(43 \%)\end{array}$ & $\begin{array}{l}45 / 82 \\
(55 \%)\end{array}$ & $\begin{array}{l}15 / 30 \\
(50 \%)\end{array}$ & $\begin{array}{l}10 / 11 \\
(91 \%)\end{array}$ \\
\hline
\end{tabular}


Fig. 2 Calibration plot

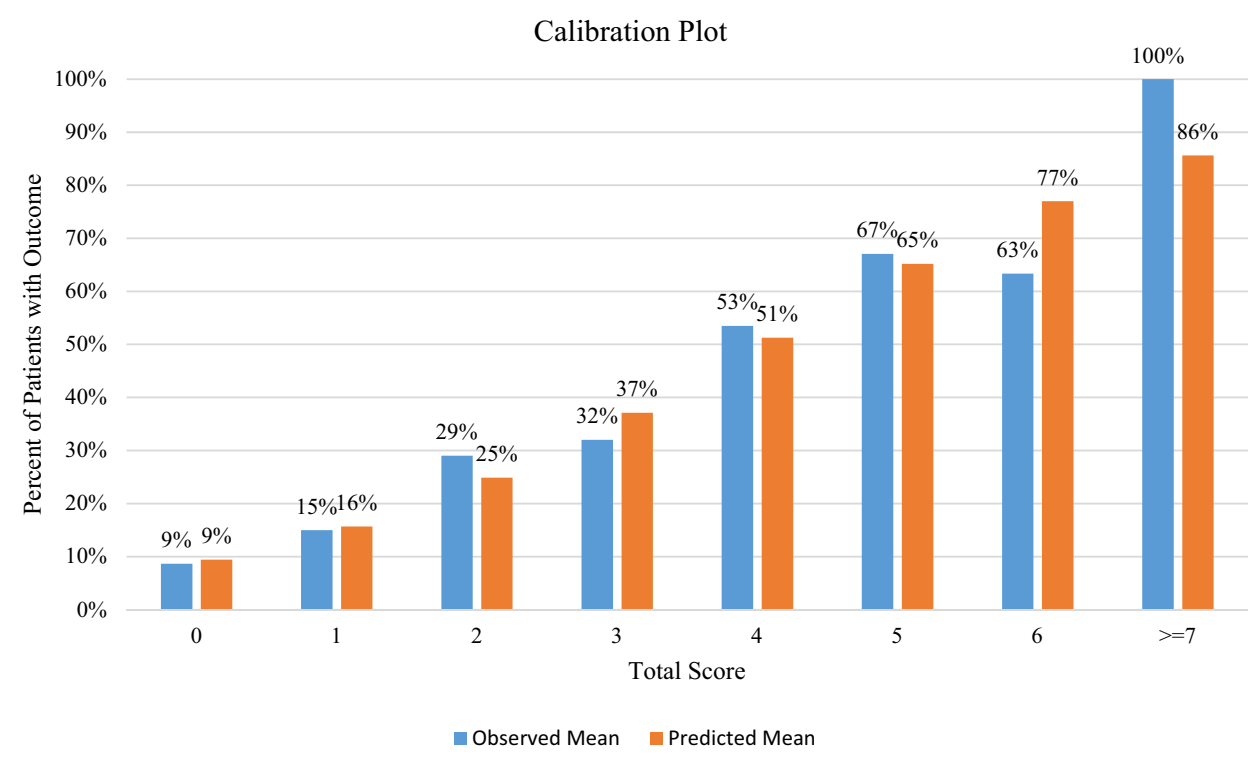

Patients' CRI scores were calculated according to the sum of CRI points they had on presentation to the ED (Table 2). The incidence of the primary outcome increased steadily with higher CRI scores (Table 3) in both the derivation and validation cohorts (area under ROC: 0.84 [derivation] and vs. 0.74 [validation]).

To validate our index, we analyzed the predictive capability of the CRI in an external cohort of 1799 sampled hospitalized patients. Supplementary Table 1 includes the baseline characteristics of the validation cohort. The validation cohort had a similar trend and distribution of the primary endpoint according to the CRI model (Table 3 ). The calibration plot (Fig. 2) reveals a close adherence between the observed and expected primary outcomes within the validation cohort.

\section{Discussion}

We describe a new risk predictive model for patients admitted with COVID-19 using easily acquired data elements in the ED. The CRI predicts the need for mechanical ventilation or inpatient death.

Although certain clinical characteristics are associated with increased mortality in COVID-19 [11], a validated disease-specific model to assess risk at the time of presentation to the ED is lacking. The CRI encompasses seven variables that were independently associated with the need for mechanical ventilation or death in patients hospitalized with COVID-19. Patients score points for age $\geq 65$ years, chronic obstructive pulmonary disease, chronic kidney disease, cerebrovascular disease, initial D-dimer $>1.1 \mu \mathrm{g} / \mathrm{mL}$, platelet count $<150 \mathrm{~K} / \mu \mathrm{L}$, and severity of $\mathrm{SpO} 2: \mathrm{FiO} 2$ ratio (Table 2). All the above variables have been shown to be associated with worse outcomes in patients with COVID-19
Table 4 Univariate odds ratio of score components within the validation cohort

\begin{tabular}{lll}
\hline CRI Predictors & $\begin{array}{l}\text { Univariate regression } \\
\text { OR }(95 \% \mathrm{CI}), P \text { value }\end{array}$ & $\begin{array}{l}\text { Multivariate regression } \\
\text { OR }(95 \% \mathrm{CI}), P \text { value }\end{array}$ \\
\hline Age $(\geq 65$ years $)$ & $2.56(2.05-3.18),<0.001$ & $1.97(1.54-2.53),<0.001$ \\
Thrombocytopenia $<150 \mathrm{~K}$ & $1.11(0.88-1.39), 0.40$ & $1.19(0.92-1.55), 0.19$ \\
D-dimer initial $\geq 1.1(\mu \mathrm{g} / \mathrm{mL})$ & $1.70(1.26-2.29),<0.001$ & $1.25(0.89-1.77), 0.19$ \\
Chronic kidney disease & $1.67(1.33-2.10),<0.001$ & $1.35(1.04-1.75), 0.03$ \\
Chronic obstructive pulmonary disease & $1.72(1.27-2.31),<0.001$ & $0.94(0.66-1.34), 0.74$ \\
Cerebrovascular disease & $1.69(1.25-2.28),<0.001$ & $1.34(0.96-1.88), 0.09$ \\
SpO2/FiO2 ratio $>300$ to $\leq 400$ & $1.50(1.16-1.95), 0.002$ & $2.12(1.59-2.82),<0.001$ \\
SpO2/FiO2 ratio $>200$ to $\leq 300$ & $7.37(4.01-13.56),<0.001$ & $10.16(5.40-19.09),<0.001$ \\
SpO2/FiO2 ratio $\leq 200$ & $13.32(8.81-20.13),<0.001$ & $16.97(11.01-26.16),<0.001$ \\
\hline
\end{tabular}

${ }^{*} \mathrm{SpO} 2 / \mathrm{FiO} 2$ ratio Reference $=>400$ 
[12-14]. However, not all variables were shown to be independently associated with the primary outcome.

There have been other clinical risk predictive models used to assist with decision-making [7, 15-17], but the CRI offers several advantages. The variables are objective and easily obtained at the time of presentation, and the scoring system is simple. A low CRI was associated with a lower risk for mechanical ventilation or death in both the derivation and validation cohorts, and the rates increased with higher scores. The score can assist in the triage of patients with lower scores to units with lower provider-to-patient ratios given the low likelihood for mechanical ventilation or death. Conversely, a higher score confers an increased risk of mechanical ventilation or death, mandating closer monitoring during admission (Table 3 ). In comparison to other score models, the CRI was validated against a larger and more heterogeneous population. It also utilized data from a more predictable time point (admission) compared to the variable time points utilized by other models.

Temporal trends indicate that the demographics and the approach to the care of COVID-19 patients have changed as the disease has evolved and clinical and research experience accumulates. The initial aggressive approach to initiate mechanical ventilation has tempered. While changing practice variations can challenge the applicability of risk models, the CRI uses objective and plausible metrics that have a strong association with the underlying disease state and we believe will maintain relevance (Table 4).

During a pandemic, and especially in areas of high case density, clinical tools and prediction models can aid in appropriate patient triage and resource allocation. The CRI is a useful tool that weighs the chance of survival with risk for ICU care, mechanical ventilation, or death, allowing for objective and efficient ED triage and management of patients admitted with COVID-19. We, therefore, suggest obtaining the CRI on admission for such patients.

\section{Limitations}

Our study is retrospective and therefore is subject to limitations. Our cohort was limited to hospitalized patients and cannot be generalized to all patients diagnosed with COVID19 as the model captures an earlier state of patient demographics, disease management, outcomes, and vaccination. Future prospective and multicenter studies should re-assess the CRI to further determine generalizability as the disease patterns change and new variants are discovered.

\section{Conclusions}

In conclusion, the CRI is an important tool that can guide early triage, inform treatment strategies, and empower physician decision-making during the COVID-19 pandemic.

Supplementary Information The online version contains supplementary material available at https://doi.org/10.1007/s11239-021-02565-6.

Funding None.

Data availability Availability of data and material as allowed per the corresponding author.

\section{Declarations}

Conflict of interest None.

Ethical approval IRB approved.

\section{References}

1. Guan WJ, Ni ZY, Hu Y, Liang WH, Ou CQ, He JX, Liu L, Shan H, Lei CL, Hui DSC, Du B, Li LJ, Zeng G, Yuen KY, Chen RC, Tang CL, Wang T, Chen PY, Xiang J, Li SY, Wang JL, Liang ZJ, Peng YX, Wei L, Liu Y, Hu YH, Peng P, Wang JM, Liu JY, Chen Z, Li G, Zheng ZJ, Qiu SQ, Luo J, Ye CJ, Zhu SY, Zhong NS, China Medical Treatment Expert Group for C (2020) Clinical characteristics of coronavirus disease 2019 in China. N Engl J Med. https://doi.org/10.1056/NEJMoa2002032

2. Wu Z, McGoogan JM (2020) Characteristics of and important lessons from the coronavirus disease 2019 (COVID-19) outbreak in China: summary of a report of 72314 cases from the Chinese Center for Disease Control and Prevention. JAMA. https://doi.org/10.1001/jama.2020.2648

3. Richardson S, Hirsch JS, Narasimhan M, Crawford JM, McGinn T, Davidson KW, Barnaby DP, Becker LB, Chelico JD, Cohen SL, Cookingham J, Coppa K, Diefenbach MA, Dominello AJ, Duer-Hefele J, Falzon L, Gitlin J, Hajizadeh N, Harvin TG, Hirschwerk DA, Kim EJ, Kozel ZM, Marrast LM, Mogavero JN, Osorio GA, Qiu M, Zanos TP (2020) Presenting characteristics, comorbidities, and outcomes among 5700 patients hospitalized with COVID-19 in the New York City area. JAMA. https://doi. org/10.1001/jama.2020.6775

4. Huang C, Wang Y, Li X, Ren L, Zhao J, Hu Y, Zhang L, Fan G, Xu J, Gu X, Cheng Z, Yu T, Xia J, Wei Y, Wu W, Xie X, Yin W, Li H, Liu M, Xiao Y, Gao H, Guo L, Xie J, Wang G, Jiang R, Gao Z, Jin Q, Wang J, Cao B (2020) Clinical features of patients infected with 2019 novel coronavirus in Wuhan, China. Lancet 395:497-506. https://doi.org/10.1016/S0140-6736(20)30183-5

5. Zhou F, Yu T, Du R, Fan G, Liu Y, Liu Z, Xiang J, Wang Y, Song B, Gu X, Guan L, Wei Y, Li H, Wu X, Xu J, Tu S, Zhang Y, Chen H, Cao B (2020) Clinical course and risk factors for mortality of adult inpatients with COVID-19 in Wuhan, China: a retrospective cohort study. Lancet 395:1054-1062. https://doi. org/10.1016/S0140-6736(20)30566-3

6. Wu C, Chen X, Cai Y, Xia J, Zhou X, Xu S, Huang H, Zhang L, Zhou X, Du C, Zhang Y, Song J, Wang S, Chao Y, Yang Z, Xu J, Zhou X, Chen D, Xiong W, Xu L, Zhou F, Jiang J, Bai C, Zheng J, Song Y (2020) Risk factors associated with acute respiratory distress syndrome and death in patients with coronavirus 
disease 2019 pneumonia in Wuhan, China. JAMA Intern Med. https://doi.org/10.1001/jamainternmed.2020.0994

7. Ji D, Zhang D, Xu J, Chen Z, Yang T, Zhao P, Chen G, Cheng G, Wang Y, Bi J, Tan L, Lau G, Qin E (2020) Prediction for progression risk in patients with COVID-19 pneumonia: the CALL score. Clin Infect Dis 71:1393-1399. https://doi.org/10. 1093/cid/ciaa414

8. Raad M, Dabbagh M, Gorgis S, Yan J, Chehab O, Dagher C, Jamoor K, Hussein IH, Cook B, Van Harn M, Singh G, McCord J, Parikh S (2020) Cardiac injury patterns and inpatient outcomes among patients admitted with COVID-19. Am J Cardiol 133:154-161. https://doi.org/10.1016/j.amjcard.2020.07.040

9. Grissom CK, Brown SM, Kuttler KG, Boltax JP, Jones J, Jephson AR, Orme JF Jr (2010) A modified sequential organ failure assessment score for critical care triage. Disaster Med Public Health Prep 4:277-284. https://doi.org/10.1001/dmp.2010.40

10. Force ADT, Ranieri VM, Rubenfeld GD, Thompson BT, Ferguson ND, Caldwell E, Fan E, Camporota L, Slutsky AS (2012) Acute respiratory distress syndrome: the Berlin definition. JAMA 307:2526-2533. https://doi.org/10.1001/jama.2012.5669

11. Mehra MR, Desai SS, Kuy S, Henry TD, Patel AN (2020) Cardiovascular disease, drug therapy, and mortality in Covid-19. N Engl J Med. https://doi.org/10.1056/NEJMoa2007621

12. Petrilli CM, Jones SA, Yang J, Rajagopalan H, O'Donnell L, Chernyak Y, Tobin KA, Cerfolio RJ, Francois F, Horwitz LI (2020) Factors associated with hospital admission and critical illness among 5279 people with coronavirus disease 2019 in New York City: prospective cohort study. BMJ 369:m1966. https://doi. org/10.1136/bmj.m1966

13. Team CC-R (2020) Preliminary estimates of the prevalence of selected underlying health conditions among patients with coronavirus disease 2019-United States, february 12-march 28, 2020. MMWR Morb Mortal Wkly Rep 69:382-386. https://doi. org/10.15585/mmwr.mm6913e2

14. Liang W, Guan W, Chen R, Wang W, Li J, Xu K, Li C, Ai Q, Lu W, Liang H, Li S, He J (2020) Cancer patients in SARS-CoV-2 infection: a nationwide analysis in China. Lancet Oncol 21:335337. https://doi.org/10.1016/S1470-2045(20)30096-6

15. Shi Y, Yu X, Zhao H, Wang H, Zhao R, Sheng J (2020) Host susceptibility to severe COVID-19 and establishment of a host risk score: findings of 487 cases outside Wuhan. Crit Care. https://doi. org/10.1186/s13054-020-2833-7

16. Liang W, Liang H, Ou L, Chen B, Chen A, Li C, Li Y, Guan W, Sang L, Lu J, Xu Y, Chen G, Guo H, Guo J, Chen Z, Zhao Y, Li S, Zhang N, Zhong N, He J (2020) Development and validation of a clinical risk score to predict the occurrence of critical illness in hospitalized patients with COVID-19. JAMA Intern Med. https:// doi.org/10.1001/jamainternmed.2020.2033

17. Galloway JB, Norton S, Barker RD, Brookes A, Carey I, Clarke BD, Jina R, Reid C, Russell MD, Sneep R, Sugarman L, Williams S, Yates M, Teo J, Shah AM, Cantle F (2020) A clinical risk score to identify patients with COVID-19 at high risk of critical care admission or death: An observational cohort study. J Infect 81:282-288. https://doi.org/10.1016/j.jinf.2020.05.064

Publisher's Note Springer Nature remains neutral with regard to jurisdictional claims in published maps and institutional affiliations. 